\title{
Controles de capitais são necessários?
}

\author{
João Basilio Pereima* \\ Alexandre Hideki Maeda Joboji* \\ Ana Luiza Clemente de Abreu Valério ${ }^{* * *}$
}

RESUMO - Os episódios recentes sobre o comportamento do câmbio no Brasil reascendeu a discussão sobre política cambial e controle de capitais, temporariamente relegada para segundo plano pela crise financeira internacional. Em termos mais amplos reascendeu a discussão sobre a pertinência de atual regime macroeconômico que combina metas de inflação, câmbio flutuante e mobilidade de capitais, para dar continuidade ao tão necessário processo sustentado de crescimento econômico e desenvolvimento social. Este artigo discute a adoção de controle de capitais e seus resultados registrados pela literatura empírica e teórica e advoga pela necessidade de implantação de controles de capitais pelos países, em função da hipertrofia dos mercados financeiros em relação à economia real. Outro motivo para adoção de controles de capitais é dispor de medidas preventivas para lidar com a excessiva liquidez das economias desenvolvidas, criada pelas políticas de combate à crise, cuja abundância inevitavelmente circulará os mercados financeiros dos países emergentes que serão os primeiros, ao que tudo indica, a elevar suas taxas de juros, entre eles o Brasil.

Palavras-chave: Controle de capitais. Crises cambiais. Macroeconomia.

\section{INTRODUÇÃO}

O controle dos movimentos de capitais financeiros internacionais não é uma ideia nova, ele existiu durante muito tempo, especialmente após os anos 1930 quando os países foram atingidos por sucessivas crises cambiais e financeiras ao fim do ciclo econômico e político de 1840-1915 que incluiu liberalização comercial, financeira e globalização. Vigorou sob diversas formas de manifestação até os anos 1990, quando começaram a ser removidos na última onda liberalizante que varreu o mundo e culminou na grande crise financeira de 2007/2009. Quase no final dos anos 1990, mais precisamente em 1997, muitos países e em especial o FMI, voltaram a tratar do tema da necessidade de controle de capitais, desta vez, forçados pela crise Asiática a qual havia estancado repentinamente o fluxo de capitais do resto

\footnotetext{
* Doutorando do Programa de Pós-Graduação em Desenvolvimento Econômico da Universidade Federal do Paraná (UFPR). Professor do departamento de Economia da Universidade Federal do Paraná (UFPR). Endereço eletrônico: joaobasilio@ufpr.br.

** Graduando em Economia pela Universidade Federal do Paraná (UFPR). Atualmente é membro da equipe técnica do Boletim Economia \& Tecnologia. Endereço eletrônico: alexandre.joboji@gmail.com.

*** Graduanda em Economia pela Universidade Federal do Paraná (UFPR). Atualmente é membro da equipe técnica do Boletim Economia \& Tecnologia. Endereço eletrônico: analuiza_valerio@yahoo.com.br.
} 
do mundo para aquela região. A discussão sobre controles de capitais ganhou evidência em 1998 quando a Malásia, um dos países asiáticos tido como exemplo da eficácia de implementação de medidas de liberalização, introduziu o controle de capitais e adotou diversas medidas restritivas, entre elas adoção de rígidos controles sobre saída de capitais.

Embora muito estudada, a relação entre câmbio/controle de capitais e crescimento econômico permanece controversa. A continuidade da controvérsia indica que a ciência econômica ainda não foi capaz de produzir afirmações categóricas e definitivas, razão pela qual o debate, que mistura inclinações ideológicas, interesses segmentados e ciência propriamente dita, prossegue intenso como nunca. A discussão sobre política cambial e controle de capitais reascendeu especialmente no Brasil devido a retomada do processo de valorização do real frente a outras moedas, especialmente o dólar americano e o yuan renmimbi da China, dois grandes "parceiros" comerciais.

A discussão sobre política cambial e especialmente sobre controles de capitais está viesada no Brasil em direção às opções ideológicas simplistas na forma de antagonismos (falsos, diga-se) entre esquerdistas com ímpetos controladores versus direitistas com ímpetos liberais. Mas como bem demonstraram Modenesi \& Modenesi (2006) países que adotaram controles de capitais (China, Índia, Malásia e Chile) nos anos 1990 o fizeram a partir de diferentes regimes políticos, alguns conservadores e liberais, outros socialistas e reformadores. Além disto, as propostas de adoção de controles de capitais foram inicialmente feitas por economistas que tradicionalmente possuem inclinações liberais, que vão desde Keynes ${ }^{1}$, D. H. White ${ }^{2}$, até nomes mais recentes como James Tobin ${ }^{3}$, Paul Davidson, Danik Rodrik e Joseph

\footnotetext{
${ }^{1}$ O longo e quase interminável debate macroeconômico entre monetaristas e keynesianos desde os anos 1960 criaram a falsa impressão, na história das idéias econômicas, de que propostas keynesianas sejam propostas esquerdistas que se opõem radicalmente às propostas liberais geralmente identificadas como pertencendo a grupos de direita. Nada mais falso. Keynes foi simplesmente um reformador do sistema capitalista, e após a grande crise de 1929 sua principal preocupação era exatamente restaurar a força do sistema capitalista e dos mecanismos de mercado, quando eles falharam, num cenário muito parecido ao da crise financeira de 2007/2009. Disse Keynes, na Teoria Geral: "Por isso, enquanto a ampliação das funções do governo (...) poderia parecer a um publicista do século XIX ou a um financista americano contemporâneo uma terrível transgressão do individualismo, eu a defendo, ao contrário, como único meio exeqüivel de evitar a destruição total das instituições econômicas atuais e como condição de um bem-sucedido exercício da iniciativa individual" (KEYNES, 1983, p. 257). Para desfazer interpretações equivocadas, creio que Keynes deixou bem claro que o papel do Governo, por ele advogado, não é de substituição, mas de complemento, aos mecanismos de mercado. Assim devem ser entendidas as propostas de controle de capitais que venham de economistas com visão keynesiana.

2 White foi economista-chefe do Tesouro Americano nos anos 1940 e foi o principal interlocutor nas negociações que criaram todo o aparato monetário internacional que ficou conhecimento como Regime de Bretton Woods. Tanto Keynes quanto White, nos poucos casos de consenso nas negociações, sugeriram à época a adoção de controles de capitais.

${ }^{3}$ James Tobin foi autor da proposta de criação de um imposto mundial sobre operações cambiais, que alimentaria um fundo de estabilização internacional, e que tinha como objetivo principal inibir fluxos especulativos de capital de curto prazo e com isso a volatilidade cambial mundo afora. Ver Tobin (1978).
} 
Stiglitz, entre inúmeros outros. Estes economistas estão longe do que se poderia chamar de macroeconomia esquerdista. O debate ideológico em torno do controle de capitais é, portanto, falso. A formação de opinião no Brasil precisa se esclarecer melhor. O problema é, digamos, técnico e diz respeito, essencialmente, sobre a capacidade do mercado regular via preços a taxa de câmbio de forma mais eficaz do que fariam os mecanismos de regulação e intervenção do Estado, como meio de proporcionar um processo de crescimento econômico sustentado e industrialização no longo prazo, ou conter crises cambiais e financeiras no curto prazo. Existem razões fortes de ambos os lados das posições que justificam tanto a abertura plena da conta de capitais, bem como sua regulação ou controle por parte do Estado. A transferência do debate técnico para o plano político deve-se ao fato de que as diferentes visões pró e contra alguma forma de controle defendam interesses econômicos específicos. Há quem ganhe com a liberalização financeira plena e há quem perca. Em termos pragmáticos, a teoria que se entende "vitoriosa" depende da capacidade de mobilização política destes diferentes grupos de interesse. Mas há casos em que a realidade se impõe sobre razões particulares e faz com que instituições representativas mudem forçadamente sua opinião, como aconteceu agora em 2010 com o FMI reconhecendo a importância dos controles de capitais.

Além disto, devemos reconhecer que no geral e no longo prą̧o as evidências empíricas econométricas, de que tanto a imposição quanto à remoção de restrições na conta de capital afetam o crescimento econômico, são inconclusivas (RODRIK, 1998; EDISON et al, 2002; ONO et al, 2006). Empiricamente não é possível nem justificar a remoção de controles nem sua imposição. Sob a perspectiva de curto prazo países que adotaram controles dos fluxos de entrada e saída de capital, com o objetivo de garantir autonomia da política monetária e reduzir vulnerabilidade, tiveram sucessos nos seus objetivos. No caso específico de controles sobre saída eles são mais eficazes se forem abrangentes e não deixarem espaços não controlados que possam ser usados pelo mercado como canais alternativos para fugir dos controles (ARYIOSHI, 2000). Estas razões foram apontadas por Aryioshi (2000) como fatores explicativos do fracasso do controle sobre fluxos de saída usados pelo Brasil no período 1993-1997.

Mas se as evidências empíricas econométricas de longo prazo dos efeitos da liberalização da conta capital sobre o crescimento econômico são inconclusivas, o mesmo não ocorre com as razões teóricas. Aqui as diferenças são evidentes e claras e a teoria se divide entre aqueles que advogam pela causa da liberalização da conta capital e os que são contra. 
Entre os extremos, há os que advogam pragmaticamente por medidas que evitem fluxos excessivos que podem causar danos à economia local, da mesma forma que o excesso de chuva pode fazer o fluxo da correnteza transbordar as margens causando destruição, não pela chuva em si, mas pelo seu excesso. Muitos se renderam à realidade e reconheceram a importância de controles de capitais como Joseph Stiglitz e o próprio FMI que passou a aceitar a adoção, mesmo que temporária, de controles em momentos singulares de crises cambiais e financeiras. Num trabalho publicado recentemente intitulado "Capital Inflows: The Role of Controls", Jonhatan D. Ostry et al (2010), vice-diretor de pesquisa do FMI, afirmam que o controle de capitais por parte de países emergentes é desejável, sob certas circunstâncias. É o reconhecimento do que uma vasta literatura no Brasil e no mundo vem afirmando há muito tempo. Não há nada novo na afirmação de Ostry, a não ser o fato de ela vir de dentro de uma instituição como FMI, tradicionalmente a favor da abertura plena da conta de capitais.

No restante deste artigo apresentamos argumentos em defesa da implantação de controles de capital no Brasil, com o objetivo de reduzir volatilidade cambial e conter tanto valorizações extremas, como a que está ocorrendo, quanto às desvalorizações abruptas (overshootings). Reduzir volatilidade, não significa eliminar volatilidade e por isso, reduzir volatilidade também não é sinônimo de câmbio fixo.

Há muitas razões teóricas que justificam a adoção de controles de capitais, já amplamente divulgadas em revistas especializadas, e por isso não iremos abordá-las de forma sistemática, mas apenas ocasionalmente quando necessário para justificar alguma das posições assumidas neste artigo. Poderemos acrescentar ao debate quatro justificativas de ordem conjuntural e mudanças estruturais para adoção de controles preventivos, por conta de especificidades da economia brasileira para a segunda década do século XXI: a.) tendência de enorme fluxo de ingresso de capitais no futuro próximo; b.) déficits crescentes e cumulativos em transações correntes podem armazenar combustível para futuros ataques especulativos; c.) políticas de desvalorizações cambiais em outros países desequilibram as transações correntes brasileiras e criam motivos adicionais para especulação cambial; d.) destino da gigantesca liquidez internacional criada pelas políticas monetárias de combate à crise poderá se dirigir aos países emergentes, desequilibrando sua conta capital, que poderão registrar elevados superávits de curto prazo valorizando mais o câmbio. 


\section{LIBERALIZAÇÃO FINANCEIRA, CRISES CAMBIAIS E INSTABILIDADE SISTÊMICA}

Os últimos 30 anos do século $\mathrm{XX}$ foram pródigos em crises cambiais, com um aumento do risco sistêmico em praticamente todos os países. Glick \& Hutchison (2004), ao estudar um painel com 69 países ao longo de 1975-1997 identificaram nada mais nada menos que 160 crises cambiais. A principal causa deste aumento foi o fim do sistema monetário de Bretton Woods em 1973. O fim da estabilidade monetária internacional, por sua vez, foi causado pela combinação de convertibilidade do dólar em ouro e pela enorme liquidez de dólares no mercado internacional. Sem uma moeda de referência estável e confiável, os países adotaram regimes de câmbio flutuante. Ao longo destes últimos 30 anos também ocorreram dois outros fenômenos que, juntamente com câmbio flutuante, criaram os contornos do que se convencionou chamar de globalização financeira. Estes dois fenômenos são a mobilidade de capitais e a hipertrofia dos mercados financeiros ${ }^{4}$.

Com a globalização, vieram também as crises cambiais e as crises financeiras. Muitas destas crises não foram geradas pela globalização em si, mas ocorreram em função de desequilíbrios internos dos países envolvidos. No entanto, na presença dos três elementos, câmbio flutuante, mobilidade de capitais e hipertrofia dos mercados financeiros, as crises se tornaram mais intensas. Por fim, a interligação tecnológica e as operações em tempo real dos mercados financeiros e investidores associadas à mobilidade criaram as condições para que crises locais contagiassem outras regiões. Sem freios e livres para circular instantaneamente ao toque de uma tecla [Enter] o "comportamento de manada" passou a operar em escala mundial com uma velocidade de contágio sem precedentes na história econômica. Países pequenos e médios, mesmo que estáveis, passaram a registrar os efeitos diversos, na maioria das vezes negativos, da saída e entrada repentina de capitais. Os países em desenvolvimento foram as vítimas principais dos intensos movimentos, dado o tamanho relativamente pequeno de seus mercados financeiros em relação aos mercados americanos e europeus.

Crises cambiais e financeiras se tornaram muito mais comuns desde 1980.

As primeiras análises de crises cambiais tiveram origem a partir dos trabalhos de Krugman em 1979. As crises cambiais analisadas por Krugman foram motivadas por

\footnotetext{
${ }^{4}$ De acordo com os relatórios anuais do McKinsey Group (2008, 2009) em 1980 havia U\$1,2 de ativos financeiros para cada US\$1,0 de PNB na economia mundial. Em 2007 esta relação aumentou para US\$3,6 e sofreu uma queda em 2008 para US $\$ 3,0$ por causa da destruição de ativos financeiros na crise. Ao longo dos últimos 20 anos os ativos financeiros cresceram 3 vezes mais que a produção das economias, evidenciando-se ai, o descolamento da valorização financeira da economia real.
} 
aumentos de importações gerados pelo financiamento do déficit fiscal (expansão da demanda agregada) com emissão de moeda. Sob o regime de câmbio fixo, à medida que os déficits comerciais prosseguem as reservas internacionais diminuem, até quando os agentes nacionais e estrangeiros se dão conta do esgotamento das reservas e trocam a moeda nacional por moeda estrangeira adiantando ainda mais o fim do regime de câmbio fixo.

As crises cambiais dos países europeus e asiáticos na década de 90 deram origem a vários casos de contágio, que consistem na ocorrência de crises cambiais e ataques especulativos sequencialmente. Em momentos de crises os investidores ficam particularmente sensíveis a pequenos eventos e sinais que antes poderiam ser considerados insuficientes ou irrelevantes. Em momentos de incerteza crescente, tais sinais ganham poder. Neste ambiente, pequenos acontecimentos podem causar grandes movimentos de capitais os quais podem desestabilizar países que em situações normais não sofreriam com saídas repentinas de capitais e parada súbita de ingresso de capitais.

O que aconteceu nos países asiáticos reforça ainda mais a teoria da combinação da crise por contágio com a fragilidade de seus sistemas financeiros. No caso asiático de 1997 houve uma concessão excessiva de crédito de médio e longo prazo lastreada por débitos de curto prazo obtidos no exterior. A crise cambial teve início quando os investidores estrangeiros decidiram resgatar seus investimentos. Os bancos asiáticos fizeram empréstimos junto ao banco central e este não teve condições de segurar essa fuga de capitais estrangeiros.

Para se proteger destes ataques especulativos muitos países, especialmente países asiáticos, passaram a acumular grandes reservas, reciclando-as no mercado financeiro mundial, aplicando boa parte em títulos do tesouro americano. O Brasil segue a mesma estratégia (WOLF, 2008; PEREIMA \& STAUB, 2009).

Esse acúmulo de reservas leva a uma situação conflitante: para que se acumulem reservas em alguns países é necessário que ocorram déficits em outros. Isto gera um desequilíbrio mundial que não poderá ser mantido por tempo indefinido, de forma que a estratégia de acumular reservas para prevenir crises cambiais torna o sistema monetário internacional mais instável, pois a polarização entre países superavitários e deficitários aumenta. Da forma como opera o sistema monetário e financeiro internacional hoje, a obtenção de estabilidade individual é construída à custa de aumento da instabilidade coletiva e isto, de modo algum, representa um equilíbrio final, no interminável jogo do sistema monetário internacional. No atual esquema, o risco sistêmico é continuamente crescente. Um colapso no sistema financeiro americano, incluindo o mercado de títulos públicos que por ora 
está fora de controle com a relação dívida/PNB subindo mais de 7,0\% pontos percentuais por ano, levaria imediatamente ao colapso das economias superavitárias cujas reservas estão aplicadas em títulos americanos. Em momentos de risco sistêmico crescente, as políticas econômicas nos países mais frágeis ou vulneráveis a grandes movimentos deveriam criar proteção prudencial, de modo a não deixar suas economias expostas. Na seção 4, adiante, argumentamos sobre quatro situações que combinadas podem expor a economia brasileira aos efeitos indesejados de um excesso de entrada de capitais.

\section{ALgUMAS HistóRIAS RECENTES DE ADOÇÃO DE CONTROLE DE CAPITAIS $^{5}$}

Ao mesmo tempo em que o número de crises cambiais e financeiras aumentou após 1973, e em especial após a década de 1980, muitos países passaram a rever suas políticas de abertura financeira e adotaram alguma variante de controle de capitais. O caso emblemático foi o da Malásia, tratado resumidamente adiante, pois se tratava de um país usado pelo FMI e Banco Mundial como exemplo a ser seguido, dado seu retrospecto de sucesso em seguir fielmente as recomendações das instituições internacionais.

Outros países como China e Índia, mesmo sofrendo pressões a favor da liberalização dos capitais, continuam a manter políticas de controle de capitais, apesar de certas medidas pontuais tomadas no sentido de promover maior liberalização financeira e produtiva. Outros países que adotaram controles de capitais, quando necessários, são os latino-americanos, Chile e Colômbia.

Uma característica comum a quase todos os países, com exceção de China e Índia, é que todos eles adotaram alguma forma de controle, após uma crise ter se instalado. Foram respostas a posteriori, implementadas por necessidade e não por vontade. A China e Índia , ao contrário, usam controles como extensão e complemento de uma política maior de crescimento e desenvolvimento econômico. Há uma grande diferença entre adotar controles após irromper uma crise e adotar controles preventivos que evitam que uma crise ocorra, ou então que minimizam os efeitos de uma crise. Os custos são menores no segundo caso, mesmo se considerados cumulativamente no médio prazo.

${ }^{5}$ Uma boa parte desta seção fez uso do estudo de Aryoshi, et al (2000). 
A seguir apresentamos muito resumidamente alguns casos ilustrativos de controles de capitais. Existem muitos detalhes não relatados e muitos outros casos não incluídos, por questões de espaço, como Espanha, Tailândia, Rússia, Argentina e outros.

\section{1 MALÁSIA - 1994-1998}

A Malásia utilizou os controles de capitais por diversas vezes. Primeiramente controlando a entrada de capitais em 1994 e posteriormente, durante a crise financeira de 1997-1998, a sua saída.

No primeiro caso, em 1994, o excesso de liquidez internacional levou a Malásia a adotar controles para conter as entradas de capitais, já que a taxa de juros doméstica e a apreciação de sua moeda, o ringgit, atraíam volumosas quantias de capitais de curto prazo para a economia. As principais medidas foram: a.) recolhimentos compulsórios não remunerados de aplicações estrangeiras em ativos domésticos; b.) limitação do acesso dos bancos locais ao endividamento externo; c.) proibição de certas transações financeiras entre bancos residentes e estrangeiros; d.) proibição dos bancos residentes venderem ativos financeiros com maturidade inferior à um ano para bancos não residentes. Todas estas medidas destinavam-se a evitar um fluxo excessivo de divisas e com isso evitar a valorização do ringgit. Além disto, elas não comprometeram o fluxo de ingresso de capital de longo prazo. Ao fim de 1994, quando cessou o excesso de ingresso de capital, as medidas foram afrouxadas.

No segundo caso, em 1998, durante a crise financeira que atingiu a Ásia em 1997, a Malásia se viu diante de um problema oposto ao de 1994. Agora ela estava enfrentando uma fuga repentina de capitais, que causou uma desvalorização de $68 \%$ em sua moeda no intervalo de pouco menos de um ano. Isto tudo teria ocorrido numa situação em que os fundamentos da economia estavam sólidos (ARYIOSHI et al, 2000, p. 100).

Para melhor entendimento do caso malaio, deve-se ter em mente uma característica peculiar que é a existência de um mercado off-shore de ringgit. A moeda malaia era utilizada como moeda de troca internacional local. Bancos em outros países da região, como Cingapura, aceitavam depósitos em ringgit, de modo que haviam dois mercados monetários interconectados: um dentro da Malásia e outro fora de suas fronteiras. Assim, medidas de controles de capitais deveriam levar em conta este aspecto. Parte das medidas tinham por 
objetivo desmontar as atividades especulativas off-shore. Além disto, a adoção de controles tinha como objetivo evitar um aumento das taxas internas de juros ${ }^{6}$.

As principais medidas de controle de saída de capitais, no front interno, foram: a.) necessidade de aprovação, para não residentes, de conversão de ringgit em moeda estrangeira; b.) proibição de repatriar aplicações financeiras vendidas, pelo prazo de 12 meses, contados a partir da data da venda dos títulos; c.) autorização prévia para residentes fazerem aplicações no exterior, a partir de um certo montante; d.) remessas de divisas por residentes, ficou limitada, no total, ao montante de remessa de divisas por não residentes, neutralizando os fluxos; e.) alíquotas de impostos progressivas sobre a venda de ativos financeiros obtidos por capital estrangeiro: quanto menor o prazo da aplicação maior a alíquota de imposto; f.) alíquotas progressivas sobre rendimentos, incluindo remessas de lucros.

Tais controles, implementados em plena crise, tinham por objetivo estancar a saída de capitais e criar condições internas para retomar o controle da política monetária, que até então deveria se ajustar aos fluxos de capitais ${ }^{7}$.

\section{2 ÍNDIA - 1991-1999}

Desde a sua independência em 1947 até inícios da década de 1990, a Índia se mostrou um país intervencionista e fechado. Durante a crise asiática de 1997 a Índia foi pouco afetada pelo fenômeno de contágio. Para alguns autores (ARYOSHI, 2000) isto talvez seja explicado pela manutenção de certas formas de controle de capitais pela Índia, a despeito das reformas liberalizantes implementadas durante os anos 1990. Por outro lado, devido ao excessivo fechamento de sua economia e aos excessivos controles de capitais e de comércio, a Índia apresentou menor crescimento na década de 1990. O processo gradual de reformas econômicas de cunho liberalizante adotadas a partir de 1991 visava remover entraves que estariam retardando o crescimento do país. Mesmo adotando medidas de liberalização para permitir maior volume de comércio e fluxos de capitais, alguns controles permaneceram ou

\footnotetext{
${ }^{6}$ Se o Brasil tivesse adotado políticas semelhantes em 1998/1999, quando a taxa de juros chegou ao absurdo 45,90\%a.a em Nov/1997, e permanecendo estratosfericamente alta em boa parte do mandato de Gustavo Franco como presidente do Banco Central, a dívida interna não teria crescido tanto. Parte da elevada dívida pública e dos altos juros que até hoje drenam as energias financeiras do país deve-se à política de juros altos deste período.

${ }^{7}$ Esta foi a escolha do Brasil. Ao perder controle sobre a política monetária, o BC, sob o comando de Gustavo Franco, teve que fazer o jogo do mercado. Mesmo assim, as elevadas taxas de juros não contiveram o movimento especulativo que culminou em 1999 no fim do plano real. O BC à época apenas enxugou gelo e protelou por mais um ano a pressão para a desvalorização do Real que se iniciou em 1997, permitindo com isso a reeleição de Fernando Henrique Cardoso. Os custos fiscais e financeiros desta aventura política são sentidos até hoje, quando o país precisa pagar aproximadamente $\mathrm{R} \$ 160$ bilhões de juros ao ano.
} 
foram aperfeiçoados. Os controles na Índia estão mais baseados em quantidades, na forma de limitações administrativas, do que incentivos ou desincentivos via mercado, na forma de impostos. Podemos citar a respeito das reformas ocorridas na década de 1990: i) as restrições sobre a entrada de capitais foram levemente afrouxadas; ii) estimularam-se os investimentos diretos estrangeiros; iii) desestimularam-se as entradas de capitais de curto prazo; e iv) geraram-se débitos futuros (como os depósitos em divisas de não-residentes indianos). Em suma, restaram sob controle administrativo: a saída de capitais e a entrada e saída de capitais de curto prazo.

No início da década de 2000, foram flexibilizadas as operações que geram débitos, tendo-se verificado modesto afrouxamento das restrições sobre a saída de capitais.

\subsection{CHINA - 1994-1999}

A China é tida como uma das economias mais controladas do mundo. Durante o período de 1994-1999, que abrangeu, portanto, o antes e o depois da crise asiática, a China adotou algumas medidas liberalizantes, mas ao mesmo tempo manteve e até intensificou alguns controles. Em geral as reformas no aparato de controle de capitais chinês favoreceram os fluxos de longo prazo em detrimento dos fluxos de capitais de curto prazo. Portanto, mesmo através do contexto atual de uma maior liberalização, a China continua controlando sua conta de capitais. Em 1996, foi adotada a livre conversibilidade das transações correntes, mas a movimentação de capitais foi objeto de limitada liberalização, vigorando ainda restrições: i) ao acesso ao mercado doméstico pelos investidores estrangeiros; ii) aos investimentos externos de residentes; iii) sobre empréstimos externos; e iv) sobre investimento direto no exterior.

\subsection{CHILE - 1991-1998}

A experiência do Chile com o uso de controle de capitais em geral procurou evitar movimentos de capitais de curto prazo. Neste sentido, sua política não difere muito da política adotada por outros países ao longo das décadas de 1980-1990.

O controle de capitais foi utilizado no Chile nos governos de Patrício Aylwin (19901994) e Eduardo Frei Ruiz Tagle (1994-2000), ambos do Partido Democrata Cristão (PDC). Dentre as principais medidas utilizadas pelo Chile, destacam-se os controles sobre a entrada de capitais de curto prazo e baseados em mecanismo de incentivo, com o objetivo de dar uma maior autonomia aos policymakers. Isto se fez necessário para que o Estado recuperasse o 
controle sobre a política monetária e pudesse adotar uma política de elevação de juros com a preservação da competitividade externa da economia chilena, então ameaçada pela previsível apreciação da moeda doméstica - decorrente da maciça entrada de recursos para aplicações de portfólio e sob a forma de empréstimos bancários. Entre as várias medidas destacam-se:

- Imposição de recolhimento de depósito compulsório ${ }^{8}$ em 1991 sobre ingressos de curto prazo, incluindo operações de crédito, no valor de $20 \%$, recolhidos em moeda estrangeira do entrante. Em 1992 o percentual aumentou para 30\%, foi reduzido para 10\% em 1998 e finalmente retirado em 1999;

- Medidas administrativas: a imposição de período mínimo de permanência dos investimentos financeiros e diretos estrangeiros e a necessidade de autorização prévia para entradas e saídas de recursos;

- Medidas regulatórias, como a exigência de nível mínimo de risco do tomador de recursos e de prazo mínimo de maturidade dos títulos lançados pelas empresas no exterior.

A crise asiática encadeou uma retração do fluxo internacional de capitais, e em junho de 1998 o recolhimento compulsório do Chile foi reduzido para $10 \%$ e extinto três meses depois. A exigência de permanência mínima por um ano dos investimentos financeiros e diretos estrangeiros foi eliminada em 2001.

\subsection{COLÔMBIA - 1993-1998}

A Colômbia também é um caso de controle de capitais orientado principalmente a reduzir fluxos de curto prazo. O controle de capitais é adotado temporariamente, ao mesmo tempo em que o país implementa uma série de reformas liberalizantes. Dentre os países relatados neste estudo a Colômbia foi o país que implementou as mais radicais reformas liberalizantes, que incluíam abertura comercial e financeira, permitindo-se inclusive, a propriedade de bancos locais pelo capital estrangeiro. Apesar disto, a Colômbia não abriu mão da adoção de controles de capitais em alguns momentos críticos, de forte ingresso de capital.

A partir de 1990, a Colômbia colocou em prática uma radical política econômica reformadora, incluindo: uma completa liberalização comercial, a liberalização das regras e regulamentos concernentes à recepção de investimento direto estrangeiro e abertura

${ }^{8}$ Denominados de Unremunerated Reserve Requirement - URR. 
controlada da conta de capitais do balanço de pagamentos. As reformas na Colômbia provocaram um enorme fluxo de capitais, muitos dos quais de curto prato. O fluxo de entrada de capitais que era de apenas 0,2\% do PNB em 1990 passou para 7,0\% em 1997. Na média do período o fluxo de entrada foi de $4,0 \%$, causando forte apreciação do peso colombiano.

A Colômbia passou a cobrar um imposto de $10 \%$ sobre transferência e serviços privados não financeiros em junho de 1992. Tal medida visava reduzir o uso de certas transações em conta corrente para fins especulativos.

Como os fluxos de entrada continuaram em setembro de 1993, a Colômbia passou a recolher depósitos compulsórios não remunerados sobre empréstimos efetuados no exterior.

Embora com intensidade menor, os fluxos de entrada ainda estavam causando valorização excessiva do peso. Defrontada com o recebimento de fortes influxos de capitais, em $1994^{9}$ as autoridades colombianas adotaram o sistema de Crawling Peg - sistema de desvalorização progressiva e controlada de uma moeda. O regime cambial Crawling Peg foi implementado pelas autoridades monetárias na tentativa de ajustar o câmbio às variáveis de inflação e juros. Antes da adoção de controle sobre a taxa de câmbio, o banco central colombiano usou de mecanismo de mercado para esterilizar o fluxo de entrada, mas diante do grande volume e do custo elevado das operações de esterilização, a estratégia mudou para o regime de câmbio administrado. A mudança também se explica pelo fato de que a política de esterilização atraía mais capital ainda por conta do diferencial dos juros internos e externos, de forma que esta política não surtia os efeitos desejados em conter a apreciação cambial. ${ }^{10} \mathrm{Com}$ essa mudança, a política macroeconômica foi precedida por uma positiva depreciação real da moeda nacional, que garantiu à economia uma reserva de liquidez para fazer frente à tensão associada aos influxos capitais que normalmente acompanham as reformas pró-mercado na América Latina. Sem essas medidas adotadas, os influxos poderiam ter sido de muito maior magnitude, em vista das expectativas gerais de reformas econômicas modernizantes e do bom desempenho da Conta de Capital colombiana.

\footnotetext{
${ }^{9} \mathrm{O}$ modelo de bandas cambiais já estava sendo informalmente praticado desde 1991. Em 1994 a Colômbia formalizou seu regime e tornou a política cambial mais rigorosa, com maior comprometimento do governo em sustentar este regime.

${ }^{10} \mathrm{O}$ mesmo mecanismo está em ação no Brasil hoje. Para evitar a apreciação do Real o BC intervém no mercado comprando moeda estrangeira. A expansão monetária que se segue é esterilizada por operações com títulos, expandindo-se a dívida pública num ambiente de elevadíssima taxa de juros.
} 


\section{RAZÕES PARA CONTROLES DE CAPITAIS PREVENTIVOS PARA O BRASIL}

As transformações recentes na economia mundial e brasileira e os eventos esperados no cenário mundial doravante estão criando condições novas que aumentam a volatilidade cambial e a tendência de valorização cambial. O caso do Brasil atual assemelha-se em muito ao caso Colombiano de 1993-1998, quando fatores conjunturais internos positivos se somaram a liquidez internacional atraindo um expressivo volume de capital financeiro de curto prazo, obrigando a Colômbia adotar alguma forma de controle sobre a entrada de capital. O mesmo processo está ocorrendo no Brasil.

\subsection{TENDÊNCIA DE ENORME FLUXO DE INGRESSO DE CAPITAIS NO FUTURO PRÓXIMO}

O crescimento da economia brasileira baseado no consumo interno tem descolado a economia brasileira da crise internacional. A atratividade do mercado interno financeiro, com elevadas taxas de juros, e de capitais com altos rendimentos na BM\&F-Bovespa, somados à perspectiva de um ambiente favorável a investimentos industriais rentáveis garantidos pelo aumento da demanda interna, faz do Brasil um polo de atração de capital financeiro e produtivo de toda ordem, tanto de capital financeiro de curto prazo, especulativo, quanto investimento estrangeiro direto. Somando-se a isso a perspectiva de ingresso de capital motivado por eventos específicos como Copa Mundial, Olimpíadas e Pré-sal, não é difícil prever que a entrada excessiva de capital tende a valorizar o câmbio e produzir grandes déficits comerciais e em transações correntes, que já estão sendo observados.

\subsection{DÉFICTS CRESCENTES E CUMULATIVOS EM TRANSAÇÕES CORRENTES}

Tendo em vista a perspectiva de ingresso crescente de capital produtivo e financeiro de toda ordem, se nada for feito, é inevitável que a valorização cambial continue. Enquanto houver fluxo de entrada via conta de capitais, o país terá a sensação de que os crescentes déficits comerciais e em transações correntes poderão ser financiados, sem comprometer o uso das reservas. Ter-se-á ainda a falsa impressão de que os déficits em transações correntes ajudam a reciclar o ingresso de capital financeiro tornando desnecessárias ou reduzindo as operações de esterilização dos fluxos de entrada promovidas pelo Banco Central. Seguindo nesta visão, estaríamos num equilíbrio de curto prazo em que o país pode importar bens de capital e bens intermediários baratos para expandir a produção interna, ao mesmo tempo em 
que recebe capital financeiro e não pressiona o mercado cambial. O perigo desta sensação de equilíbrio é considerá-lo como uma posição estável. Este equilíbrio é eminentemente instável. Basta alguma flutuação negativa do fluxo de capitais e ter-se-á uma corrida cambial. Tendo em vista a mobilidade quase plena de capitais e o elevado volume de capital financeiro de curto prazo operando no país, a probabilidade de ocorrência de overshooting cambial é grande. Há na economia brasileira combustível suficiente, na forma de capital de curto prazo armazenado, para uma grande explosão. Faltam no momento os motivos para sua ignição. Assim, um regime de controle de capitais prudencial deveria desde já diminuir o estoque local de material inflamável, na forma de capital financeiro de curto prazo, que tem como objetivo apenas aproveitar a onda de valorizações do mercado de capitais e fazer operações de carrytrade para aproveitar o elevado diferencial de juros oferecido pelo Brasil.

\subsection{POLÍTICAS DE DESVALORIZAÇÕES CAMBIAIS EM OUTROS PAÍSES}

A crise financeira mundial e a consequente depressão e estagnação que se instalou nas principais economias desenvolvidas reduziram drasticamente o volume e os preços do comércio internacional. No caso dos preços, boa parte da redução se deve ao esvaziamento das bolhas especulativas nos mercados futuros. A queda do comércio internacional tem afetado as economias exportadoras, como a Alemanha e o Japão, bem como os países com modelos de crescimento até então baseados em exportação, como a China e demais asiáticos. Estes países exportadores têm duas opções apenas para sustentar o nível de atividade de suas economias: tornar seus produtos mais competitivos no mercado internacional aumentando a produtividade e inovação e ao mesmo tempo desvalorizar suas moedas. Produtividade e inovação andam a passos mais lentos, portanto resta como estratégia de resposta rápida a desvalorização cambial, que é o que está fazendo o EUA e China. A China não pode ainda, sustentar todo seu crescimento baseado apenas em demanda interna. Ela ainda precisa exportar e por isso está demorando em permitir uma valorização do Yuan, a despeito das pressões internacionais.

É neste ambiente de recrudescimento da competição do comércio internacional que a valorização cambial promovida pela livre movimentação de capitais no Brasil colocará o país numa posição perdedora no jogo internacional. Ao mesmo tempo em que sua taxa de inovação tecnológica não acompanha o resto mundo, seu câmbio permanece valorizado.

60 


\subsection{GIGANTESCA LIQUIDEZ INTERNACIONAL DA PÓS-CRISE}

Além dos fatores acima, o contexto monetário e inflacionário também desempenha um papel chave na dinâmica de ajuste da economia brasileira. $\mathrm{O}$ mix macroeconômico atual, que combina metas de inflação, câmbio flutuante, mobilidade plena de capitais e poupança externa envolve altos riscos. O cenário mundial de baixa taxa de juro combinado com o cenário da alta taxa de juro combina-se de forma perfeita para que haja no futuro um novo motivo para que parte do capital financeiro mundial mova-se para a economia brasileira. Alega-se que a expectativa (por enquanto não passa disso...) de aumento dos juros americanos de 0,25\%a.a para 1,00\%a.a em 2010, os déficits em transações correntes em elevação em 2010 e os efeitos já contabilizados do IOF de $2 \%$ seriam suficientes para conter, e até mesmo reverter, a tendência de valorização cambial. Quanto aos efeitos dos déficits em transações e a cobrança de IOF não há dúvidas que de isto evita a valorização.

Acontece que o atual regime macroeconômico, que supervaloriza a opinião financeira, está lutando ferrenhamente para impor um consenso sobre a necessidade de aumentar os juros de curto prazo o mais rápido possível. Se isso acontecer, o aumento dos juros americanos em nada contribuirá, e as operações de carry trade vão prosseguir mais fortes do que nunca. Havendo motivos reais para valorização, mesmo que pequena, especuladores estrangeiros e nacionais poderão facilmente montar posições vendidas em dólar futuro. Tais posições forçam o mercado a promover mais valorização ainda a fim de aumentar seu cupom cambial à medida que se aproximam os vencimentos dos contratos. Então o que seria uma pequena valorização cambial, se converte numa valorização alavancada por mercados futuros com efeitos sobre a inflação, o que exigirá maiores taxas de juros e mais carry trade com impactos negativos sobre o crescimento econômico. O mesmo mecanismo atua na direção oposta, no caso da ocorrência de déficits estruturais em transações correntes. O ajuste cambial no Brasil é pró-cíclico e tende a potencializar movimentos de valorização e desvalorização. Este é um resultado indesejado que justifica adoção de controles de capitais em regimes de metas de inflação.

\section{CONCLUSÃO}

As diversas experiências históricas observadas em vários países que adotaram reformas liberalizantes demonstraram que nenhum destes países abriu mão de um nível mínimo de controle de capitais, para fazer frente a mudanças conjunturais e estruturais na economia ao longo dos anos 1990. Embora cada país seja um caso, podemos tirar uma lição 
de todas estas experiências. Com exceção da China, todos os casos recorreram a controles após uma crise ter se instalado. É evidente que a estratégia de apagar um incêndio depois de algum tempo produz muito prejuízo. É neste sentido que controles prudenciais de capitais devem ser adotados.

Tomando-se os motivos expostos na seção 4, é perceptível que a trajetória futura da economia brasileira conduz a um aumento do risco sistêmico pela entrada excessiva de capital financeiro e a correlata valorização cambial que daí advém. Os contextos interno e externo combinam-se virtuosamente para promover mais valorização cambial e maior exposição cambial de curto prazo. O caso brasileiro atual é semelhante à posição da Colômbia em 19931998 e desta forma o país deveria, desde já, adotar formas de controle de entradas de capitais, especialmente os capitais de curto prazo. Além de reduzir combustível de queima rápida, muitas vezes explosivo, que causaria grandes overshooting, o país evitará a repetição do lamentável ciclo de expansão da dívida causada pela política monetária de Gustavo Franco em 1997 e 1998. Em permanecendo o atual modelo macroeconômico, não há dúvidas de que o Banco Central irá combater overshooting cambial com elevação de juros.

O custo fiscal desta política seria muito maior do que a adoção de algum esquema de controle prudencial de entrada de capitais.

\section{REFERÊNCIAS}

ARYIOSHI, A. et al. Capital controls: country experiences with their use and liberalization, Washington: IMF Occasional Paper, n. 172.

EDISON, HALI J.; KLEIN, MICHAEL; RICCI, LUCA ANTONIO; Sløk, Torsten. Capital account liberalization and economic performance: survey and synthesis, IMF Working Paper, n. 02/120.

GLICK, REUVEN; HUTCHINSON, MICHAEL. Capital controls and exchange rate instability in developing countries, Journal of International Money and Finance, v. 24, p. 387.412 .

KEYNES, JOHN M. Teoria geral do emprego, do juro e da moeda. Coleção Os Economistas, São Paulo: Abril, Cultural, 1985.

KRUGMAN, PAUL. Currency crises, NBER Conference.

McKinsey Global Institute. Mapping global capital markets: Fifht annual report, EUA.

McKinsey Global Institute. Global capital markets: Entering a new era, EUA.

MODENESI, A. de M; MODENESI, R. L. Controle de capitais: uma proposta de esquerda? in: SICSU, J \& FERRALI Filho, F. (orgs); Câmbio e controle de capitais: avaliando a eficiência de modelos macroeconômicos, Rio de Janeiro: Elsevier. 
OSTRY, JONATHAN D. et al. Capital inflows: the role of controls, IMF Staff Position Note, February 19, 2010, SPN/10/04

PEREIMA, JOÃO BASILIO; STAUB, GERALDO. A Macroeconomia da crise e as oportunidades para o Brasil, Boletim de Economia e Tecnologia, vol.15, p. 45-56, out/dez 2008.

Rodrick, Danik. Who needs capital-account convertibility?. Essays in International Finance, Princeton, n. 207.

TOBIN, JAMES. A proposal for international monetary reform. Eastern Economic Journal, vol. 4, p. 153-159.

WOLF, MARTIN. Fixing Global Finance, The Johns Hopkins University Press, EUA.

WYPLOSZ, C. Financial restraints and liberalization in postwar Europe, in: CAPRIO, G; HONOHAN, P. STIGLITZ, J. (orgs); Financial Liberalization, How Far, How Fast. Cambridge University Press. 
